\title{
Divisions asymétriques ovocytaires / Asymmetric divisions in oocytes
}

Centre interdisciplinaire de recherche en biologie (CIRB)

Marie-Hélène Verlhac

\section{OpenEdition}

\section{Journals}

Electronic version

URL: https://journals.openedition.org/annuaire-cdf/16183

DOI: $10.4000 /$ annuaire-cdf. 16183

ISBN: 978-2-7226-0572-5

ISSN: 2109-9227

\section{Publisher}

Collège de France

\section{Printed version}

Date of publication: 30 December 2020

Number of pages: $670-672$

ISBN: 978-2-7226-0516-9

ISSN: 0069-5580

\section{Electronic reference}

Marie-Hélène Verlhac, "Divisions asymétriques ovocytaires / Asymmetric divisions in oocytes", L'annuaire du Collège de France [Online], 118 | 2020, Online since 01 April 2021, connection on 22 August 2022. URL: http://journals.openedition.org/annuaire-cdf/16183; DOI: https://doi.org/10.4000/ annuaire-cdf.16183 
III. ÉQUIPES ACCUEILLIES

AU COLLÈGE DE FRANCE 



\title{
CENTRE INTERDISCIPLINAIRE DE RECHERCHE EN BIOLOGIE (CIRB)
}

\author{
CONTRÔLE MOLÉCULAIRE DU DÉVELOPPEMENT NEURO-VASCULAIRE / \\ MOLECULAR CONTROL OF NEURO-VASCULAR DEVELOPMENT
}

Responsable : Isabelle BRUNET

\section{RECHERCHE}

Pages web : https://www.college-de-france.fr/site/en-cirb/brunet.htm.

Neuronal and vascular development require a refined spatio-temporal orchestration to guide axons and vascular plexus through the organism, align vessels with nerves, and allow appropriate functional connections to establish between the two systems. Indeed, accurate neuro-vascular crosstalk is of tremendous importance as it regulates many vital aspects of body homeostasis such as neuronal activity and plasticity, blood pressure and heart rate.

In order to elucidate the functional aspects of neurovascular interactions, we are focusing on arterial innervation. Previous studies have established that arteries guide axons of the sympathetic nervous system toward their targets (Mukouyama Y.S et al., 2002, 2005; Glebova N.O. and Ginty D.D., 2005; Makita T. et al., 2008). Nevertheless, arteries themselves are also target for sympathetic innervation to exert a control of arterial blood pressure. Indeed, innervation of peripheral resistance arteries by autonomic sympathetic nerves controls response to stress and blood supply to organs by regulating vascular tone (Storkebaum E. et al., 2011). This feature turns out to be critical for the regulation of homeostasis. In addition, resistance arteries bridge major elastic arteries of the arterial tree to the capillary network that perfuse all organs and tissues to provide oxygen and nutrients locally. A failure in properly regulating the caliber and vasoconstriction of resistance arteries could have devastating consequences on this vascular bed as an inappropriately high blood flow would then arise into capillaries and result in its destruction and bleeding. This vasoconstriction is the result at the cellular level of arterial smooth muscle cells (SMCs) contraction upon Noradrenalin release at the neuro-vascular junction (NVJ) site, wich is a synapse «en passant» between sympathetic axon and SMCs (Burnstock G., 2008; Luff S.E., 1996). Despite the fundamental importance of blood flow control and vascular tone, signals controlling the development of sympathetic arterial innervation remain unknown.

We first determined the developmental time window when arterial innervation is initiated, and found that arterial innervation begins during early postnatal development, two days after birth (P2). Comparing the transcriptomes of non- 
innervated (P0) versus innervated arteries (P2), we identified 300 genes up-regulated in $\mathrm{P} 2$ arteries, and many encoded axon guidance factors, suggesting their possible implication in arterial innervation. We identified the axon guidance cue Netrin-1 as an essential factor required for development of arterial innervation in mice. Netrin-1 is produced by SMCs at the onset of innervation and signals via its receptor deleted in colorectal cancer (DCC) to attract sympathetic growth cones. Function-blocking approaches including cell-type specific deletion of the genes encoding Ntn-1 in SMCs and $D c c$ in sympathetic neurons led to severe and selective reduction of sympathetic innervation and to defective vasoconstriction in resistance arteries. These findings reveal a novel role for Netrin-1 and DCC critical for the control of arterial innervation and blood flow regulation in peripheral organs (Brunet et al., JCI, 2014; Eichmann and Brunet, Science Translational Medecine, 2014).

In addition, we identified two other molecules produced by arteries, Contactin-1 and Ephrin-A4, each of them controlling arterial innervation via a different mechanism, and involved in cardiovascular function regulation, suggesting that cardiovascular innervation is a finely tuned process (Simonnet and Brunet; Martin and Brunet, in preparation). Ephrin-A4 is a repulsive axon guidance molecule expressed by arteries to avoid inappropriate innervation via the receptor EPHA4 present in sympathetic neurons. Mice inactivated for EPHA4 selectively in sympathetic neurons exhibit hyper-innervated arteries, associated with an enhanced vasoconstriction. Contactin-1, expressed by arteries, is involved in axonal branching to generate new neuronal fibers at the onset of arterial innervation, as a loss of contactin-1 generate a decreased arterial innervation in vivo.

Finally, we showed that arterial sympathetic innervation occurs during arteriogenesis and arterial maturation, and this innervation is maintained during adulthood. Furthermore, sympathetic innervation is found on the entire arterial tree, including large elastic arteries such as the aorta, and cerebral arteries. Nevertheless, those arteries do not rely on sympathetic innervation to vasocontrict and regulate blood flow. This suggests that sympathetic innervation might be playing other roles in this context, such as arterial wall maturation or release of neuronal factors to the benefit of the artery. We are currently addressing those issues in adult mice models with conditional (THcreERT2) and/or transitory (DREADD) sympathetic innervation levels increased or enhanced.

\section{PUBLICATION}

Simonnet É., Martin-Pires S., Pardanaud L., Henrion D., Silvestre J.S. et Brunet I., «Ephrin-A4/EphA4 signaling in arterial innervation development and physiology», in preparation. 


\title{
RÉSEAUX DE SYSTÈMES ÉVOLUTIFS / NETWORK IN EVOLUTIONARY SYSTEMS
}

\author{
Responsable : Anton CROMBACH
}

\section{Publication}

Verd B., Clark E., Wotton K.R., Janssens H., JiméneZ-Guri E., Crombach A. et JAEGER J., «A damped oscillator imposes temporal order on posterior gap gene expression in Drosophila », PLOS Biology, vol. 16, $\mathrm{n}^{\mathrm{o}}$ 2, 2018, e2003174, [première version DOI : 10.1101/068072], DOI : 10.1371/journal.pbio.2003174.

\section{DYNAMIQUE DES CHROMOSOMES / CHROMOSOME DYNAMICS}

\author{
Responsable : Olivier ESPÉLI
}

\section{RECHERCHE}

Page web : https://www.college-de-france.fr/site/en-cirb/espeli.htm.

\section{PuBlications}

EL SAYYED H. et ESPÉLI O., « Mapping E. coli Topoisomerase IV binding and activity sites », Methods in Molecular Biology, vol. 1703, 2018, p. 87-94, DOI : 10.1007/978-1-4939-74597_6.

Leh H., Khodr A., Bouger M.-C., Sclavi B., Rimsky S. et Bury-Moné S., «Bacterialchromatin structural proteins regulate the bimodal expression of the locus of enterocyte effacement (LEE) pathogenicity island in enteropathogenic Escherichia coli », MBio, vol. 8, $\mathrm{n}^{\mathrm{o}}$ 4, 2017, DOI : 10.1128/mBio.00773-17.

DemarRe G., Prudent V. et EspéLI O., « Imaging the cell cycle of pathogen E. coli during growth in macrophage », Methods in Molecular Biology, vol. 1624, 2017, p. 227-236, DOI : 10.1007/978-1-4939-7098-8_17.

VICKRIDGE E., PLANCHENAULT C. et EsPÉLI O., « Revealing sister chromatid interactions with the loxP/Cre recombination assay », Methods in Molecular Biology, vol. 1624, 2017, p. 29-37, DOI : 10.1007/978-1-4939-7098-8_3.

Vickridge E., Planchenault C., Cockram C., Junceda I.G. et Espéli O., « Management of E. coli sister chromatid cohesion in response to genotoxic stress », Nature Communications, vol. 8, 2017, 14618, DOI : 10.1038/ncomms14618.

Muller H., Scolari V.F., Agier N., Piazza A., Thierry A., Mercy G., DescorpsDeclere S., LaZar-Stefanita L., Espeli O., Llorente B., Fischer G., Mozziconacci J. et Koszul R., "Characterizing meiotic chromosomes' structure and pairing using a designer sequence optimized for Hi-C », Molecular Systems Biology, vol. 14, nº 7, 2018, e8293, DOI : 10.15252/msb.20188293. 


\title{
CiRCUITS NEURONAUX ET COMPORTEMENT / NEURAL CIRCUITS AND BEHAVIOR
}

\author{
Responsable : Alexander FLEISCHMANN
}

\section{RECHERCHE}

Page web : https://www.college-de-france.fr/site/en-cirb/fleischmann.htm.

\section{RÔLE DES PROTÉINES MATRICIELLES DANS L'HYPOXIE ET L'ANGIOGENÈSE / ROLE OF MATRIX PROTEINS IN HYPOXIA AND ANGIOGENESIS}

\author{
Responsable : Stéphane GERMAIN
}

\section{RECHERCHE}

Page web : https://www.college-de-france.fr/site/en-cirb/germain.htm.

The sequence of biological events that permits an organism to maintain tissue viability in hypoxia remains poorly understood. Variations in oxygen concentration lead to respiratory, metabolic and vascular adaptations in tissues. How hypoxic endothelial cells (EC) integrate chemical signals with mechanical cues from their local tissue microenvironment in order to produce functional capillary networks that exhibit specialized form remains an open question. A key role of hypoxia in the regulation of many endothelial functions (Ferratge et al.) is nevertheless well established and growing evidence show that angiogenesis, defined as the events leading to blood vessels formation by sprouting or growth of preexisting vessels, can be triggered by hypoxia, both during development and in pathological conditions such as in muscle (Latroche et al.; Gitiaux et al.), in cardiovascular ischemia (Bouleti et al.; Garcia et al.) and tumors (Bousseau et al.). Our team is also interested in understanding how angiogenesis and vascular integrity are regulated in hypoxic conditions. We are also analyzing ECM composition, deposition, posttranslational modifications and rearrangement by ECs. We studied ow vascular ECM is organized and scaffolded to provide structural support for blood vessels and described how it regulates endothelial cell and pericyte functions and how it is required for proper vascular morphogenesis and maintenance of vascular homeostasis (Germain et al.; Marchand et al.).

\section{PUBLICATIONS}

Bouleti C., MonNot C. et GERMAIN S., «ANGPTL4, a multifaceted protein at the cross-talk between metabolism and cardiovascular disorders », International Journal of Cardiology, vol. 256, 2018, p. 2, DOI : 10.1016/j.ijcard.2017.10.123. 
Latroche C., Weiss-Gayet M., Muller L., Gitiaux C., Leblanc P., Liot S., BenLarbi S., Abou-Khalil R., Verger N., Bardot P., Magnan M., Chrétien F., Mounier R., Germain S. et ChAZAud B., "Coupling between myogenesis and angiogenesis during skeletal muscle regeneration is stimulated by restorative macrophages », Stem Cell Reports, vol. 9, no 6, 2017, p. 2018-2033, DOI : 10.1016/j.stemcr.2017.10.027.

Gitiaux C., Latroche C., Weiss-Gayet M., Rodero M.P., Duffy D., Bader Meunier B., Glorion C., Nusbaum P., Bodemer C., Mouchiroud G., Chelly J., Germain S., DEsGuerre I. et ChaZAud B., «Myogenic progenitor cells exhibit IFN type I-driven proangiogenic properties and molecular signature during juvenile dermatomyositis », Arthritis \& Rheumatology, vol. 70, $\mathrm{n}^{\circ}$ 1, 2018, p. 134-145, DOI : 10.1002/art.40328.

\section{ÉVOLUTION ET DÉVELOPPEMENT DES CELLULES GERMINALES / EVOLUTION AND DEVELOPMENT OF GERM CELLS}

Responsable : Jean-René HuYNH

\section{RECHERCHE}

Pages web : https://www.college-de-france.fr/site/en-cirb/huynh.htm et http://germcells.fr.

\section{Publication}

Clémot M., Molla-Herman A., Mathieu J., Huynh J.-R. et Dostatni N., «The replicative histone chaperone CAF1 is essential for the maintenance of identity and genome integrity in adult stem cells », Development, vol. 145, n 17,2018 , DOI : 10.1242/dev.161190.

\section{MODĖLES ALÉATOIRES POUR L'INFÉRENCE DE L'ÉVOLUTION DU VIVANT / STOCHASTIC MODELS FOR THE INFERENCE OF LIFE EVOLUTION (SMILE)}

Responsable : Amaury LAMBERT

\section{RECHERCHE}

Page web : https://www.college-de-france.fr/site/en-cirb/lambert.htm.

Dirigée par Amaury Lambert (professeur à Sorbonne Université), l'équipe SMILE regroupe des mathématiciens et des biologistes de l'évolution (quatre chercheurs titulaires et huit non titulaires). 
L'objectif général du groupe SMILE est de comprendre, de modéliser et d'inférer les processus évolutifs en distinguant trois échelles de temps :

1) l'échelle de temps micro-évolutive (démographie, extinctions);

2) l'échelle de temps méso-évolutive (différenciation des populations pouvant aller jusqu'à la spéciation) ;

3) l'échelle de temps macro-évolutive (diversification des espèces).

Nous nous intéressons en particulier à l'évolution des pathogènes, notamment depuis l'arrivée de François Blanquart (CNRS) dans l'équipe.

\section{1) Échelle micro-évolutive}

Nous étudions depuis quelques années la génétique des populations branchantes, dans le but de détecter la présence de sélection naturelle ou de démographie dans les données génomiques. Cette année, nous avons obtenu de nouveaux résultats concernant la structure d'un échantillon uniforme de taille fixée dans une population en expansion (Lambert, Theoret. Pop. Biol., 2018), une décomposition du spectre de fréquence des mutations en fonction de la position des mutations dans l'arbre généalogique qui permet de comprendre l'influence de cet arbre sur les données (Ferretti et al., Genetics, 2017), et une nouvelle méthode d'inférence sous un modèle combinant démographie hors d'équilibre et sélection (Matuszewki et al., Genetics, 2018).

Prolongements mathématiques. Nous avons étudié la structure allélique d'une grande population par un arbre continu muni d'une mesure de masse, en présence de mutations poissoniennes (Duchamps et Lambert, Ann. Appl. Probab., 2018) et nous avons partiellement identifié le processus des pertes successives, par dérive génétique, des types présents initialement dans une population (Achaz et al., J. Appl. Probab., à paraître).

\section{2) Échelle méso-évolutive}

Afin de comprendre la façon dont se forment les espèces à partir de l'accumulation de mutations responsables de l'isolement reproducteur, nous avons étudié l'état d'équilibre stochastique d'un processus à valeurs dans les graphes aléatoires, dont les arêtes modélisent l'interfertilité entre populations (Bienvenu et al., Stoch. Process. Their Appl. 2018, à paraitre).

G. Achaz a contribué à des recherches plus appliquées sur cette échelle de temps, chez la levure : la compréhension des processus d'apparition de novo (à partir de séquence non codante) de gènes, qui sont généralement petits, riches en GC et faiblement transcrits (Vakirlis et al., Mol. Biol. Evol., 2018) et l'identification de nouveaux processus mutationnels en l'absence de division cellulaire, où les insertions-délétions sont plus fréquentes qu'au cours des divisions (Gangloff et al., eLife 2017).

Prolongements mathématiques. Grâce au contour des arbres de Crump-ModeJagers, E. Schertzer et F. Simatos ont postulé de ranger leurs limites d'échelle en trois classes d'universalité, dont la première est constituée des arbres de Lévy (Schertzer et Simatos, Electronic Journal of Probability, 2018). En démontrant l'invariance des excursions des processus de Lévy réfléchis par certaines transformations trajectorielles dites « de rotation », M. Dávila Felipe et A. Lambert 
ont caractérisé le comportement de ces généalogies continues au voisinage de leur extinction (Dávila Felipe et Lambert, Electronic Journal of Probability, 2018).

\section{3) Échelle macro-évolutive}

Nous avons construit un cadre général permettant d'analyser et d'inférer les situations où des caractères quantitatifs évoluent de concert dans des espèces différentes, suivant un processus gaussien (Manceau et al., Systematic Biology, 2017).

Nous avons utilisé un modèle individu-centré de radiation adaptative pour analyser in silico la façon dont les taux de diversification (spéciation et extinction) dépendent de la diversité présente. Nos résultats montrent que la diversification d'un clade se fait en trois étapes: 1) taux constants, 2) ralentissement graduel du taux de spéciation, 3) explosion du taux d'extinction au-delà d'une capacité maximale (Aguilée et al., Nature Commun., 2018).

Dans le but de comprendre s'il existe un signal phylogénétique du risque d'extinction, nous avons proposé un nouveau modèle à trois paramètres réglant le déséquilibre de l'arbre phylogénétique ainsi que l'âge et le risque d'extinction de ses plus petits sous-arbres par rapport à ses plus grands sous-arbres. Nos résultats indiquent que les plus petits clades sont statistiquement les plus âgés et concentrent les plus grands risques d'extinction par espèce, nous amenant à craindre une perte rapide de diversité phylogénétique dans les décennies à venir (Maliet et al., Systematic Biology, à paraître).

Prolongements mathématiques. Les cours donnés par A. Lambert sur les modèles probabilistes pour les arbres phylogénétiques ont donné lieu à publication de deux articles de survol (Lambert, Brazilian Journal of Probability, 2017 ; Lambert, ESAIM Proceedings \& Surveys, 2018). Inspirés par la phylogénétique, où les généalogies de gènes sont emboîtées dans les phylogénies d'espèces, nous avons identifié tous les coalescents emboîtés markoviens (Blancas et al., Electronic Journal of Probability, 2018).

\section{4) Épidémiologie évolutive}

Nos résultats dans cette partie proviennent principalement des travaux de François Blanquart et de ses collaborateurs. Ceux-ci ont notamment montré que la coexistence entre souches sensibles et résistantes aux antibiotiques peut être expliquée par des interactions avec des gènes contrôlant la durée de portage de la bactérie. Chez Streptococcus pneumoniae, l'association prédite entre la résistance et les sérotypes conférant une durée de portage plus longue est vérifiée (Lehtinen et al., PNAS, 2017).

En utilisant un ensemble de données de 2028 patients infectés par le VIH entre 1985 et 2013 provenant de cinq pays européens, ils ont estimé l'héritabilité de la charge virale de patient à patient à environ $30 \%$ (Blanquart et al., PLoS Biology 2017).

Ils ont également développé un modèle décrivant l'évolution de la résistance aux antibiotiques et ont révélé ainsi l'existence d'une sélection stabilisatrice exercée sur la résistance aux antibiotiques, typiquement 2 à 5 fois plus forte que la sélection directionnelle pour cette résistance (Blanquart et al., Proc. Biol. Sci., 2017).

Prolongements mathématiques. Dans deux articles parus dans la revue Interface, nous avons étudié par des modèles mathématiques les conditions favorisant l'émergence d'une souche résistante aux antibiotiques (Blanquart et al., J. Roy. Soc. 
Interface, 2018) et l'issue de la compétition entre deux souches dans de petites populations hôtes (Parsons et al., J. Roy. Soc. Interface, à paraître).

\section{PUBLICATIONS}

Blancas A., Duchamps J.-J., LAMBert A. et SiRI-JÉGousse A., « Trees within trees: Simple nested coalescents », Electronic Journal of Probability, vol. 23, 2018, 94, DOI : 10.1214/18EJP219 [arXiv: 1803.02133].

FELIPE M.D. et LAMBERT A., «Branching processes seen from their extinction time via path decompositions of reflected Lévy processes », Electronic Journal of Probability, vol. 23, 2018, 98, DOI : 10.1214/18-EJP221.

Vakirlis N., Hebert A.S., Opulente D.A., Achaz G., Hittinger C.T., Fischer G., COON J.J. et LAFONTAINE I., «A molecular portrait of de novo genes in yeasts », Molecular Biology and Evolution, vol. 35, no 3, 2018, p. 631-645, DOI : 10.1093/molbev/msx315.

Landoulsi Z., LaAtar F., Noé E., Mrabet S., Ben Djebara M., Achaz G., Nava C., BAUlaC S., KACEM I., GARGOURI-BERRECHID A., GOUIDER R. et LEGUERN E., « Clinical and genetic study of Tunisian families with genetic generalized epilepsy: Contribution of CACNA1H and MAST4 genes », Neurogenetics, vol. 19, $\mathrm{n}^{\circ} 3$, 2018, p. 165-178, DOI : 10.1007/s10048-018-0550-z.

ACHAZ G., « 4 - Which model(s) explain biodiversity? », in P. GRANDCOLAS et M.-C. MAUREL (dir.), Biodiversity and Evolution, Amsterdam, Elsevier, 2018, p. 39-61, DOI : 10.1016/B978-1-78548-277-9.50004-8.

SCHERTZER E. et SiMATOS F., « Height and contour processes of Crump-Mode-Jagers forests (I): General distribution and scaling limits in the case of short edges », Electronic Journal of Probability, vol. 23, 2018, p. 67, DOI : 10.1214/18-EJP151.

*Blanquart F., Lehtinen S., Lipsitch M. et Fraser C., « The evolution of antibiotic resistance in a structured host population », Journal of the Royal Society, Interface, vol. 15, $n^{\text {o }} 143,2018$, DOI : 10.1098/rsif.2018.0040.

LAMBERT A., «The coalescent of a sample from a binary branching process », Theoretical Population Biology, vol. 122, 2018, p. 30-35, DOI : 10.1016/j.tpb.2018.04.005.

DUCHAMPS J.-J. et LAMBERT A., «Mutations on a random binary tree with measured boundary », The Annals of Applied Probability, vol. 28, no 4, 2018, p. 2141-2187, DOI : 10.1214/17-AAP1353.

Aguilée R., GASCUEl F., LAMBERT A. et FERrIERE R., « Clade diversification dynamics and the biotic and abiotic controls of speciation and extinction rates ", Nature Communications, vol. 9, no 1, 2018, p. 3013, DOI : 10.1038/s41467-018-05419-7.

LAMBERT A., «Random ultrametric trees and applications », ESAIM: Proceedings and Surveys, vol. 60, 2017, p. 70-89, DOI : 10.1051/proc/201760070.

SCHERTZER E., «Renewal structure of the Brownian taut string », Stochastic Processes and their Applications, vol. 128, no 2, 2018, p. 487-504, DOI : 10.1016/j.spa.2017.05.004.

Bridel S., Olsen A.-B., Nilsen H., Bernardet J.-F., Achaz G., Avendaño-Herrera R. et Duchaud E., "Comparative genomics of tenacibaculum dicentrarchi and "Tenacibaculum finnmarkense" highlights intricate evolution of fish-pathogenic species », Genome Biology and Evolution, vol. 10, no 2, 2018, p. 452-457, DOI : 10.1093/gbe/evy020.

Matuszewski S., Hildebrandt M.E., AChaz G. et Jensen J.D., « Coalescent processes with skewed offspring distributions and nonequilibrium demography », Genetics, vol. 208, $\mathrm{n}^{\mathrm{o}}$ 1, 2018, p. 323-338, DOI : 10.1534/genetics.117.300498.

Bienvenu F., AKÇAy E., Legendre S. et MCCAndlish D.M., «The genealogical decomposition of a matrix population model with applications to the aggregation of stages », 
Theoretical Population Biology, vol. 115, 2017, p. 69-80, DOI : 10.1016/j.tpb.2017.04.002. Ferretti L., LedDA A., WieHE T., ACHAZ G. et Ramos-Onsins S.E., « Decomposing the site frequency spectrum: The impact of tree topology on neutrality tests », Genetics, vol. 207, n 1 , 2017 , p. 229-240, DOI : 10.1534/genetics.116.188763.

Gangloff S., Achaz G., Francesconi S., Villain A., Miled S., Denis C. et ARCANGIOLI B., « Quiescence unveils a novel mutational force in fission yeast », ELife, vol. 6, 2017, DOI : 10.7554/eLife.27469.

Blanquart F., Wymant C., Cornelissen M., Gall A., Bakker M., Bezemer D., Hall M., Hillebregt M., Ong S.H., Albert J., Bannert N., Fellay J., Fransen K., Gourlay A.J., GRABOWSKI M.K., GUNSENHEIMER-BARTMEYER B., GÜNTHARD H.F., KiVelä P., Kouyos R., LAEYendecKer O., LitTSOla K., MEYER L., PORTER K., Ristola M., VAn Sighem A., Vanham G., Berkhout B., Kellam P., Reiss P., Fraser C. et BEEHIVE COLLABORATION, "Viral genetic variation accounts for a third of variability in HIV-1 setpoint viral load in Europe », PLoS biology, vol. 15, n 6, 2017, e2001855, DOI : 10.1371/ journal.pbio.2001855.

*Blanquart F., Lehtinen S. et Fraser C., « An evolutionary model to predict the frequency of antibiotic resistance under seasonal antibiotic use, and an application to Streptococcus pneumoniae », Proceedings. Biological Sciences, vol. 284, $\mathrm{n}^{\circ}$ 1855, 2017, DOI : 10.1098/ rspb.2017.0679.

*Lehtinen S., Blanquart F., Croucher N.J., Turner P., Lipsitch M. et Fraser C., «Evolution of antibiotic resistance is linked to any genetic mechanism affecting bacterial duration of carriage », Proceedings of the National Academy of Sciences of the United States of America, vol. 114, no 5, 2017, p. 1075-1080, DOI : 10.1073/pnas.1617849114.

BAILEY S.F., BLANQUART F., BATAILLON T. et KASSEN R., « What drives parallel evolution?: How population size and mutational variation contribute to repeated evolution », BioEssays: News and Reviews in Molecular, Cellular and Developmental Biology, vol. 39, $\mathrm{n}^{\circ}$ 1, 2017, p. 1-9, DOI : 10.1002/bies.201600176.

PARSOnS T.L., LAMBERT A., DAY T. et GANDON S., « Pathogen evolution in finite populations: slow and steady spreads the best », Journal of the Royal Society, Interface, vol. 15, $\mathrm{n}^{\circ} 147$, 2018, DOI : 10.1098/rsif.2018.0135.

SCHERTZER E. et STAVER A.C., « Fire spread and the issue of community-level selection in the evolution of flammability », Journal of the Royal Society, Interface, vol. 15, $\mathrm{n}^{\circ}$ 147, 2018, DOI : 10.1098/rsif.2018.0444.

Maliet O., Gascuel F. et LAMBERT A., «Ranked tree shapes, nonrandom extinctions, and the loss of phylogenetic diversity ", Systematic Biology, vol. 67, n 6, 2018, p. 1025-1040, DOI : 10.1093/sysbio/syy030.

LAMBERT A. et SCHERTZER E., « Recovering the Brownian coalescent point process from the Kingman coalescent by conditional sampling », Bernoulli, [sous presse], http://arxiv.org/ abs/1611.01323.

LAmbert A., PinA V.M. et SChERTZER E., Chromosome Painting, 2018, https://hal.archivesouvertes.fr/hal-01850398. 


\title{
NEUROPEPTIDES CENTRAUX ET RÉGULATIONS DE L'ÉQUILIBRE HYDRIQUE ET DES FONCTIONS CARDIOVASCULAIRES / \\ CENTRAL NEUROPEPTIDES IN THE REGULATION OF BODY FLUID HOMEOSTASIS AND CARDIOVASCULAR FUNCTIONS
}

\author{
Responsable : Catherine LLORENS-CORTES
}

\section{RECHERCHE}

Page web : https://www.college-de-france.fr/site/en-cirb/llorens-cortes.htm.

\section{1) Le système rénine-angiotensine cérébral (SRAc)}

Nous avons montré dans le SRAc que l'aminopeptidase A (APA) est l'enzyme responsable de la formation de l'angiotensine III (AngIII). Nous avons ensuite identifié que, à l'encontre de ce qui est établi à la périphérie où l'angiotensine II est le facteur vasoconstricteur, au niveau central, c'est l'AngIII qui exerce un effet stimulateur tonique sur le contrôle de la pression artérielle (PA) chez le rat hypertendu. Cela suggérait que l'APA cérébrale représentait une nouvelle cible thérapeutique pour le traitement de l'hypertension artérielle (HTA). Grâce à une collaboration étroite entre notre laboratoire et les chimistes du laboratoire du $\mathrm{Pr}$ B.P. Roques, qui ont mis à profit les informations que nous avions obtenues sur l'organisation du site actif de l'APA par modélisation moléculaire et mutagénèse dirigée, les premiers inhibiteurs spécifiques et sélectifs de cette enzyme dont l'EC33 et sa prodrogue, le RB150, ont vu le jour. Nous avons ensuite montré que le RB150 administré oralement chez le rat hypertendu traverse les barrières intestinale, hépatique et hématoencéphalique, pénètre dans le cerveau, inhibe l'activité de l'APA cérébrale et normalise la PA pendant plusieurs heures, 1) en diminuant la sécrétion d'AVP dans la circulation sanguine, ce qui augmente la diurèse et diminue le volume sanguin, 2) en réduisant le tonus sympathique qui diminue les résistances vasculaires et 3) en améliorant la fonction du baroréflexe. Le RB150 renommé firibastat par l'Organisation mondiale de la santé a ensuite été évalué dans deux études cliniques phases Ia et Ib conduites chez le volontaire sain, en traitement aigu ou chronique, avec le soutien de l'ANR et de la société Quantum Genomics. Les résultats ont montré que le RB150 est cliniquement bien toléré chez l'homme après administration orale jusqu'à $750 \mathrm{mg}$, deux fois par jour pendant sept jours. Cela a permis de démarrer un essai clinique phase IIa du firibastat chez des patients hypertendus, étude multicentrique, randomisée, en double aveugle, contre placebo à laquelle le laboratoire a participé, coordonnée par le Pr M. Azizi, directeur du CIC de l'HEGP. Cette étude a apporté les premières données d'efficacité du firibastat chez des sujets hypertendus par rapport au placebo. Cet essai clinique a inclus 34 patients ayant une tension artérielle diurne comprise entre $135 / 85 \mathrm{mmHg}$ et $170 / 105 \mathrm{mmHg}$. La moitié d'entre eux a reçu le firibastat et l'autre moitié un placebo, pendant quatre semaines. Les quatre semaines suivantes, la répartition des médicaments a été inversée. Les résultats montrent que la pression artérielle systolique (PAS) a été mieux contrôlée sous firibastat avec une baisse de la PAS de - 4,7 $\mathrm{mmHg}$ en moyenne contre 
$+0,1 \mathrm{mmHg}$ sous placebo. Ces résultats encourageants ont permis la mise de place de l'étude de phase IIb (NEW HOPE), réalisée aux États-Unis sur un groupe de 256 patients hypertendus en surpoids à haut risque cardiovasculaire, coordonnée par le Pr F. Keith et sponsorisée par la société Quantum Genomics. L'étude a confirmé l'efficacité du firibastat, avec une baisse significative de PAS de près de $10 \mathrm{mmHg}$ après deux mois de traitement, y compris chez les patients afro-américains qui ont le plus souvent une hypertension résistante aux traitements actuellement disponibles. Ces résultats ouvrent la voie à un essai clinique essentiel de phase III avec le firibastat dans le traitement de l'hypertension résistante. Par ailleurs, une autre application du firibastat dans l'insuffisance cardiaque (IC) après infarctus du myocarde a vu le jour. Nous avons montré qu'un traitement par le RB150 pendant 28 jours chez le rongeur IC après infarctus du myocarde normalise l'hyperactivité sympathique et améliore de façon très significative la fonction cardiaque et diminue l'hypertrophie et la fibrose cardiaques.

\section{2) Étude d'un neuropeptide vasoactif : l'apéline}

En recherchant un récepteur spécifique de l'AngIII, nous avons isolé un récepteur orphelin couplé aux protéines $\mathrm{G}$ qui s'est révélé être le récepteur d'un nouveau peptide: l'apéline. Nous avons caractérisé pharmacologiquement ce récepteur, établi dans le cerveau du rat sa distribution et observé que l'apéline et son récepteur sont coexprimés avec l'AVP dans les neurones magnocellulaires vasopressinergiques. Nous avons mis en évidence que l'apéline, injectée par voie icv chez la rate en lactation, diminue l'activité électrique phasique des neurones vasopressinergiques, la sécrétion d'AVP dans la circulation sanguine et induit une diurèse aqueuse. L'effet aquarétique de l'apéline n'est pas uniquement dû à un effet central, mais implique aussi un effet de l'apéline au niveau du rein. Nous avons montré que l'apéline augmente le flux sanguin rénal et inhibe l'insertion des aquaporines de type 2 à la membrane apicale des canaux collecteurs provoquée par l'AVP, augmentant ainsi la diurèse. Nous avons établi chez le rat déshydraté que l'apéline et l'AVP sont régulées de façon opposée, afin de maintenir l'équilibre hydrique de l'organisme, en optimisant la sécrétion systémique d'AVP, évitant ainsi une perte d'eau supplémentaire au niveau rénal. Nous avons aussi mis en évidence en collaboration avec le CIC de l'HEGP qu'une telle régulation croisée apéline/AVP existait chez l'homme, montrant que l'apéline représente comme l'AVP, l'un des principaux (neuro)peptides vasoactifs impliqué dans le maintien de l'équilibre hydrique, aussi bien chez l'homme que chez le rongeur. Sachant que la demi-vie de l'apéline est de l'ordre de la minute, nous avons été les premiers à développer des analogues de l'apéline-17 métaboliquement stables actifs par voie systémique, en collaboration avec l'équipe de chimistes du Dr D. Bonnet à Illkirch (UMR 7200 CNRS). Ces analogues ont une affinité subnanomolaire pour le récepteur de l'apéline et une demi-vie supérieure à 24 heures dans le plasma et de $4 \mathrm{~h} 30$ dans la circulation sanguine après injection par voie sous-cutanée. Une seule injection par voie sous cutanée pour une dose de l'ordre du nmol par kg normalise pendant plus de 7 heures la pression artérielle dans un modèle expérimental d'hypertension, montrant que ces composés sont de puissants antihypertenseurs. Des études sont en cours pour explorer les effets de ces composés dans le développement de l'IC après infarctus du myocarde. 


\title{
Publications
}

Gerbier R., Alvear-Perez R., Margathe J.-F., Flahault A., Couvineau P., Gao J., De Mota N., Dabire H., li B., Ceraudo E., Hus-Citharel A., Esteoulle L., Bisoo C., Hibert M., BerdeauX A., ITURrioz X., Bonnet D. et Llorens-CorTes C., « Development of original metabolically stable apelin-17 analogs with diuretic and cardiovascular effects », FASEB journal, vol. 31, no 2, 2017, p. 687-700, DOI : 10.1096/fj.201600784R.

Couvineau P., de Almeida H., Maigret B., Llorens-Cortes C.* et Iturrioz X.*, «Involvement of arginine 878 together with $\mathrm{Ca} 2+$ in mouse aminopeptidase A substrate specificity for N-terminal acidic amino-acid residues », PloS One, vol. 12, n 9, 2017, e0184237, DOI : 10.1371/journal.pone.0184237. *Co-last authors

Marc Y., Hmazzou R., Balavoine F., Flahault A. et Llorens-Cortes C., «Central antihypertensive effects of chronic treatment with RB150: An orally active aminopeptidase A inhibitor in deoxycorticosterone acetate-salt rats », Journal of Hypertension, vol. 36, $\mathrm{n}^{\circ} 3$, 2018, p. 641-650, DOI : 10.1097/HJH.0000000000001563.

Flahault A., Trystram D., NAtaf F., Fouchard M., KNEbelmann B., Grünfeld J.-P. et JOLY D., «Screening for intracranial aneurysms in autosomal dominant polycystic kidney disease is cost-effective », Kidney International, vol. 93, $\mathrm{n}^{\mathrm{o}}$ 3, 2018, p. 716-726, DOI : 10.1016/j.kint.2017.08.016.

Chollet C., Placier S., Chatziantoniou C., Hus-Citharel A., Caron N., Roussel R., ALHENC-GELAS F. et BOUBY N., «Genetically increased angiotensin I-converting enzyme alters peripheral and renal vascular reactivity to angiotensin II and bradykinin in mice », American Journal of Physiology. Heart and Circulatory Physiology, vol. 314, $\mathrm{n}^{\mathrm{o}}$ 2, 2018, p. H350-H358, DOI : 10.1152/ajpheart.00356.2017.

\section{FORMATION ET ÉVOLUTION DES PATRONS DE COLORATION / FORMATION AND EVOLUTION OF COLOR PATTERNS}

\author{
Responsable : Marie MANCEAU
}

\section{RECHERCHE}

Page web : https://www.college-de-france.fr/site/en-cirb/manceau.htm.

\section{PUBLICATION}

Haupaix N., Curantz C., Bailleul R., Beck S., Robic A. et Manceau M., « The periodic coloration in birds forms through a prepattern of somite origin », Science (New York, N.Y.), vol. 361, no 6408, 2018, DOI : 10.1126/science.aar4777. 


\title{
BIOlOgie STATISTIQUe / Statistical BIOLOGY
}

\author{
Responsable : Olivier RIVOIRE
}

\section{RECHERCHE}

Page web : https://www.college-de-france.fr/site/en-cirb/rivoire.htm.

Notre équipe cherche à comprendre les principes sous-jacents aux capacités d'adaptation des systèmes biologiques. Notre approche est inspirée de la physique statistique et combine des analyses de séquences génomiques, des expériences quantitatives in vitro et des modèles mathématiques. Nos projets actuels sont organisés autour de trois systèmes modèles: les anticorps, les protéases et les génomes bactériens.

Nos résultats récents comprennent le développement de méthodes statistiques pour étudier la co-évolution dans les séquences de protéines et de génomes, le développement d'expériences d'évolution d'anticorps par la méthode de phage display et le développement de modèles mathématiques d'évolution de populations sujettes à des environnements fluctuants.

\section{PuBLiCATIONS}

Mayer A., Mora T., Rivoire O. et WalczaK A.M., «Transitions in optimal adaptive strategies for populations in fluctuating environments », Physical Review. E, vol. 96, n 3-1, 2017, 032412, DOI : 10.1103/PhysRevE.96.032412.

JUNIER I., FRÉMONT P. et RIVOIRE O., « Universal and idiosyncratic characteristic lengths in bacterial genomes », Physical Biology, vol. 15, nº 3, 2018, 035001, DOI : 10.1088/1478-3975/ aab4ac.

\section{INTERACTIONS NEUROGLIALES EN PHYSIOPATHOLOGIE CÉRÉBRALE / NEUROGLIAL INTERACTIONS IN CEREBRAL PHYSIOPATHOLOGY}

\author{
Responsable : Nathalie ROUACH
}

\section{RECHERCHE}

Page web : https://www.college-de-france.fr/site/en-cirb/rouach.htm.

The main goal of our group is to determine whether and how the underexplored glial cells, which are the very abundant non neuronal but yet active cells of the brain, play a role in brain information processing. We investigate the molecular modalities and functional outcomes of neuroglial interactions in physiological and pathological conditions, focusing ex vivo or in vivo on neuronal excitability, synaptic transmission, plasticity and synchronization, as well as on cognitive functions. To do so, we use a 
multidisciplinary approach combining electrophysiology, imaging, behavioral testing, mathematical modeling, and molecular tools acting selectively on astrocytes in mice and human tissues.

Using this strategy, we primarily investigated in the last year the role of astrocytes in network activity in normal and pathological conditions as well as the mechanisms underlying astroglial regulation of synaptic function. In particular we explored the impact of several factors on neurotransmission, including (1) pannexin 1 (Px1) channels, (2) Cx30-dependent mechanism underlying astroglial plasticity during development (1). In this context, we also developed a novel approach to study astroglial structural plasticity (3).

We found that Px1, a protein homolog to connexins and which forms membrane channels, controls seizure generation in human cortical post-operative tissues from epileptic patients and in a mouse model of temporal lobe epilepsy (Dossi et al., 2018). Px1 channels are indeed strongly activated in ictogenic condition and contribute to seizures by promoting and sustaining ictal activity. Such control occurs in tissues from epileptic patients with different pathologies and developmental profiles and is mediated by ATP release and activation of P2 receptors. These data suggest that Px1 may be a therapeutic target against various human epilepsies.

Similarly, we found that energy metabolism plays a key role in epileptic seizures. We indeed found that combining nutritional strategies with a low [fat]:[proteins + carbohydrates] protects against seizures to the same extent as the ketogenic diet, a well-established non-pharmacological treatment known to be effective in reducing seizure frequency in pharmaco-resistant patients, but which is however extremely restrictive and can be associated with complications caused by the high [fat]:[carbohydrate + protein] ratio (Dallérac et al., 2018). These results provide evidence that low-fat dietary strategies more palatable than the ketogenic diet could be useful in epilepsy.

We also recently revealed that $\mathrm{Cx} 30$, one of the two astroglial gap junction channel subunit, which is a determinant of astroglial synapse coverage controlling synaptic efficacy and hippocampal-based memory via an unprecedented non channel function controlling the astroglial coverage of synapses (Pannasch et al., 2014), also controls the morphology and polarity of migrating astrocytes during postnatal development via its non-channel function (Ghézali et al., 2018). We indeed found that $\mathrm{Cx} 30$ sets the orientation of astroglial motile protrusions via modulation of the laminin/ $\beta 1$ integrin/Cdc 42 polarity pathway. Connexin 30 indeed reduces laminin levels, inhibits the redistribution of the $\beta 1$-integrin extracellular matrix receptors, and inhibits the recruitment and activation of the small Rho GTPase Cdc42 at the leading edge of migrating astrocytes. In vivo, connexin 30, the expression of which is developmentally regulated, also contributes to the establishment of hippocampal astrocyte polarity during postnatal maturation. This study thus reveals that Cx30 controls astroglial polarity during development.

The plasticity of the cytoskeleton architecture and membrane properties is important for the establishment of cell polarity, adhesion and migration. We developed a novel approach, which combines stimulated emission depletion (STED) super-resolution imaging and atomic force microscopy (AFM), to correlate cytoskeletal structural information with membrane physical properties in live astrocytes (Curry et al., 2017). Using this methodology we illustrate that scratch-induced migration induces cytoskeleton remodeling caused by a polarization of actin and microtubule elements within astroglial cell processes, which strongly correlates with changes in cell stiffness. 
The method opens new avenues for the dynamic probing of the membrane structural and functional plasticity of live brain cells. It can also be used to provide new insights into mechanisms of cell structural remodeling during physiological or pathological processes, such as brain development or tumorigenesis.

\title{
PUBLICATIONS
}

DALLÉRAC G., ZAPATA J. et ROUACH N., « Versatile control of synaptic circuits by astrocytes: where, when and how? », Nature Reviews. Neuroscience, vol. 19, $\mathrm{n}^{\circ}$ 12, 2018, p. 729-743, DOI : 10.1038/s41583-018-0080-6.

Dossi E., Blauwblomme T., Moulard J., Chever O., Vasile F., Guinard E., Le Bert M., Couillin I., Pallud J., Capelle L., Huberfeld G. et Rouach N., «Pannexin-1 channels contribute to seizure generation in human epileptic brain tissue and in a mouse model of epilepsy », Science Translational Medicine, vol. 10, n 443, 2018, DOI : 10.1126/scitranslmed. aar3796.

Rouach N., Duc K.D., Sibille J. et Holcman D., « Dynamics of ion fluxes between neurons, astrocytes and the extracellular space during neurotransmission », Opera Medica et Physiologica, vol. 4, no 1, 2018, p. 1-18, DOI : 10.20388/omp2018.001.0053.

Ghézali G., Calvo C.-F., Pillet L.-E., Llense F., Ezan P., Pannasch U., Bemelmans A.-P., Etienne ManNeville S. et Rouach N., « Connexin 30 controls astroglial polarization during postnatal brain development », Development, vol. 145, $\mathrm{n}^{\circ} 4,2018$, DOI : 10.1242/dev.155275.

Mazaré N., Gilbert A., Boulay A.-C., Rouach N. et Cohen-Salmon M., « Connexin 30 is expressed in a subtype of mouse brain pericytes », Brain Structure and Function, vol. 223, $\mathrm{n}^{\circ}$ 2, 2018, p. 1017-1024, DOI : 10.1007/s00429-017-1562-4.

Boulay A.-C., Gilbert A., Oliveira Moreira V., Blugeon C., Perrin S., Pouch J., Le Crom S., Ducos B. et Cohen-Salmon M., "Connexin 43 controls the astrocyte immunoregulatory phenotype », Brain Sciences, vol. 8, $\mathrm{n}^{\circ}$ 4, 2018, DOI : 10.3390/ brainsci8040050.

Dossi E., Vasile F. et RouACH N., «Human astrocytes in the diseased brain », Brain Research Bulletin, vol. 136, 2018, p. 139-156, DOI : 10.1016/j.brainresbull.2017.02.001.

\section{RÉGULATION MOLÉCULAIRE DE LA SYNAPTOGENÈSE CHEZ LA SOURIS / MICE, MOLECULES AND SYNAPSE FORMATION}

\author{
Responsable : Fekrije SELIMı
}

\section{RECHERCHE}

Page web : https://www.college-de-france.fr/site/en-cirb/selimi.htm.

\section{PuBLICATION}

González-Calvo I. et Selimi F., «Expression and role of Galectin-3 in the postnatal development of the cerebellum », BioRxiv, 2018, p. 364760, DOI : 10.1101/364760. 


\title{
COMMUNICATION INTERCELLULAIRE ET INFECTIONS MICROBIENNES / INTERCELLULAR COMMUNICATION AND MICROBIAL INFECTIONS
}

\author{
Responsable: Guy Tran VAN NHIEU
}

\section{RECHERCHE}

Au cours des deux dernières décennies, il est devenu évident que, comme décrit pour les cellules eucaryotes, la sous-localisation des protéines dans les bactéries joue un rôle clé dans leur fonction ou leur régulation spatiotemporelle [1, 2]. Cependant, contrairement aux cellules eucaryotes, les bactéries ne contiennent pas de membranes intracellulaires délimitant les compartiments internes. Ainsi, la localisation des protéines bactériennes repose sur d'autres mécanismes encore mal compris, dont certains sont spécifiques à certaines espèces bactériennes. En particulier, le mécanisme sous-jacent à la localisation de protéines cytoplasmiques «fonctionnelles» au niveau de pôles bactériens a fait l'objet de débats, car les agrégats amorphes sont également décrits comme étant exclus des nucléoïdes des cellules bactériennes pour s'accumuler aux pôles [3]. La localisation des agrégats de protéines dans une région dépourvue de nucléoïde peut s'expliquer par un encombrement moléculaire et une entrave à la diffusion. Ce processus est appelé « occlusion par le nucléoïde », terme utilisé à l'origine sur la base de l'observation que le nucléoïde empêche la formation de l'anneau de division conduisant à la septation bactérienne [4]. De petits agrégats de protéines alimentent la croissance amorphe de gros agrégats, expliquant leur accumulation préférentielle au niveau d'un pôle ou bipolaire [3]. Cependant, outre les agrégats, des protéines «fonctionnelles » peuvent également s'accumuler au niveau des pôles bactériens, caractéristique essentielle à leur fonction. Deux mécanismes principaux ont été proposés pour la localisation polaire. L'un est un mécanisme de diffusion-capture qui ne se limite pas aux pôles bactériens, mais peut également expliquer la localisation des protéines sur d'autres sites. Cependant, dans de nombreux cas, comme pour les protéines de division cellulaire, la nature du déterminant de localisation primaire polaire est restée indéterminée [5]. La localisation polaire peut être déterminée par la capacité d'une protéine à détecter l'augmentation de la courbure des lipides membranaires négatifs au niveau des pôles bactériens [2]. En variante, la liaison des protéines périphériques à la cardiolipine, un phospholipide qui s'accumule de préférence dans les membranes incurvées négativement au niveau du pôle bactérien, pourrait conduire à la localisation polaire $[1,2]$. Le deuxième mécanisme proposé pour la localisation polaire est l'exclusion de la protéine native formant de grandes structures oligomères par le nucléoïde [2,3]. Diverses protéines, notamment les autotransporteurs, ont montré une localisation unipolaire [6]. La protéine de surface cellulaire Shigella IcsA responsable de la motilité intracellulaire à base d'actine représente probablement le paradigme de la localisation unipolaire chez les bactéries reliées à Escherichia coli. La localisation polaire IcsA résulte de sa localisation intra-bactérienne au pôle avant la sécrétion [7]. Le mécanisme sousjacent à la localisation unipolaire IcsA n'est pas complètement compris. Le chaperon DnaK a été identifié comme étant requis pour la polarisation IcsA dans un écran de génome large de protéines fusionnées à la protéine fluorescente verte (GFP), mais la 
façon dont ce chaperon contrôle la localisation polaire IcsA n'a pas été clarifiée [8]. Dans des travaux antérieurs, nous avions montré qu'avant le contact avec les cellules, le composant translocon IpaC de Shigella de type III se localisait également à un pôle bactérien et que cette localisation polaire déterminait la sécrétion de type III de type polaire lors de l'invasion des cellules hôtes par Shigella [9]. La localisation unipolaire de IpaC parallèle celle d'IcsA et n'est pas liée à l'agrégation de protéines car les protéines au pôle s'échangent avec les protéines du reste du corps bactérien. Fait intéressant, ces expériences de chasse ont indiqué que le pool d'IpaC polaire est soumis à un contrôle protéolytique à l'état d'équilibre [9]. Nous avons utilisé une approche biochimique pour identifier les protéines impliquées dans la polarisation de IpaC. Nos travaux récents montrent que le chaperon DnaK (HSP70) contrôle la localisation unipolaire du substrat de sécrétion de Shigella IpaC de type III [10]. Tout en empêchant la formation d'agrégats létaux IpaC, DnaK favorise l'incorporation d'IpaC dans de larges complexes dynamiques (LCDs) restreints au pôle bactérien par occlusion par le nucléoïde [10]. Contrairement aux polymères et aux agrégats stables, les LCDs sont réversibles et indiquent que l'occlusion de nucléoïde s'applique également aux réseaux formés par des interactions transitoires. Une analyse par recouvrement de fluorescence après photoblanchiment (FRAP) a montré que les complexes DnaK-IpaC s'échangent entre pôles opposés et que les LCDs incorporent des substrats immatures dans un processus assisté par la machine DnaKJE [10]. Ces découvertes révèlent un rôle essentiel pour les LCDs en tant que réservoirs de substrats fonctionnels de la chaperone DnaK, pouvant être rapidement mobilisés pour la sécrétion déclenchée lors du contact bactérien avec les cellules hôtes.

\section{Références citées}

[1] KiRKPATRICK C.L. et ViollieR P.H., « Poles apart: Prokaryotic polar organelles and their spatial regulation », Cold Spring Harbor Perspectives in Biology, vol. 3, $\mathrm{n}^{\mathrm{o}} 3$, 2011, DOI : 10.1101/cshperspect.a006809.

[2] LALOUX G. et JACOBS-WAGNER C., «How do bacteria localize proteins to the cell pole? », Journal of Cell Science, vol. 127, 2014, p. 11-19, DOI : 10.1242/jcs.138628.

[3] Winkler J., Seybert A., König L., Pruggnaller S., Haselmann U., SourJik V., WeisS M., Frangakis A.S., Mogk A. et Bukau B., «Quantitative and spatio-temporal features of protein aggregation in Escherichia coli and consequences on protein quality control and cellular ageing », The EMBO journal, vol. 29, no 5, 2010, p. 910-923, DOI : 10.1038/ emboj.2009.412.

[4] Wu L.J. et ERRINGTON J., « Nucleoid occlusion and bacterial cell division », Nature Reviews. Microbiology, vol. 10, no 1, 2011, p. 8-12, DOI : 10.1038/nrmicro2671.

[5] Haeusser D.P. et Margolin W., «Splitsville: Structural and functional insights into the dynamic bacterial Z ring », Nature Reviews. Microbiology, vol. 14, n 5, 2016, p. 305-319, DOI : $10.1038 /$ nrmicro.2016.26.

[6] Jain S., van Ulsen P., Benz I., Schmidt M.A., Fernandez R., Tommassen J. et GOLDBERG M.B., «Polar localization of the autotransporter family of large bacterial virulence proteins », Journal of Bacteriology, vol. 188, $\mathrm{n}^{\circ}$ 13, 2006, p. 4841-4850, DOI : 10.1128/ JB.00326-06.

[7] Charles M., Pérez M., Kobil J.H. et Goldberg M.B., «Polar targeting of Shigella virulence factor IcsA in Enterobacteriacae and Vibrio », Proceedings of the National Academy of Sciences of the United States of America, vol. 98, n 17, 2001, p. 9871-9876, DOI : 10.1073/ pnas. 171310498. 
[8] Janakiraman A., Fixen K.R., Gray A.N., Niki H. et Goldberg M.B., «A genomescale proteomic screen identifies a role for DnaK in chaperoning of polar autotransporters in Shigella », Journal of Bacteriology, vol. 191, no 20, 2009, p. 6300-6311, DOI : 10.1128/ JB.00833-09.

[9] Jaumouillé V., Francetic O., Sansonetti P.J. et Tran Van Nhieu G., « Cytoplasmic targeting of IpaC to the bacterial pole directs polar type III secretion in Shigella », The EMBO Journal, vol. 27, nº 2, 2008, p. 447-457, DOI : 10.1038/sj.emboj.7601976.

[10] Collet C., Thomassin J.-L., Francetic O., Genevaux P. et Nhieu G.T.V., « Protein polarization driven by nucleoid exclusion of DnaK(HSP70)-substrate complexes », Nature Communications, vol. 9, no 1, 2018, p. 2027, DOI : 10.1038/s41467-018-04414-2.

\section{PuBlications}

Thomassin J.-L., Santos Moreno J., Guilvout I., Tran Van Nhieu G. et Francetic O., «The trans-envelope architecture and function of the type 2 secretion system: new insights raising new questions », Molecular Microbiology, vol. 105, n 2, 2017, p. 211-226, DOI : 10.1111/mmi.13704.

Collet C., Thomassin J.-L., Francetic O., Genevaux P. et Tran Van Nhieu G., « Protein polarization driven by nucleoid exclusion of DnaK(HSP70)-substrate complexes », Nature Communications, vol. 9, no 1, 2018, p. 2027, DOI : 10.1038/s41467-018-04414-2.

Smail Y., Sun C., Combettes L. et Tran VAn Nhieu G., «Imaging $\mathrm{Ca}^{2+}$ responses during Shigella infection of epithelial cells », Journal of Visualized Experiments, $\mathrm{n}^{\mathrm{o}}$ 135, 2018, DOI : $10.3791 / 57728$.

Valencia-Gallardo C., Bou-Nader C., Aguilar D., Carayol N., Quenech'Du N., PeCQueur L., PARK H., FonteCAVE M., IZARD T. et NhIEU G.T.V., « Cell adhesion promoted by a unique Shigella IpaA vinculin- and talin-binding site », BioRxiv, 2018, 329136, DOI : $10.1101 / 329136$.

Tran Van Nhieu G., Dupont G. et Combettes L., « $\mathrm{Ca}^{2+}$ signals triggered by bacterial pathogens and microdomains », Biochimica Et Biophysica Acta. Molecular Cell Research, vol. 1865 , no 11 B, 2018, p. 1838-1845, DOI : 10.1016/j.bbamcr.2018.08.007.

\section{PHYSIQUE MULTI-ÉCHELLE DE LA MORPHOGÉNĖSE / MULTISCALE PHYSICS OF MORPHOGENESIS}

Responsables : Hervé TURLIER

\section{RECHERCHE}

Page web : https://www.college-de-france.fr/site/en-cirb/Turlier.htm.

\section{Introduction}

Invaluable progress has been made last decades in the molecular, genetic and cellular characterization of morphogenetic processes. Yet, the precise physical processes governing the shape and dynamics of cells remain poorly characterized. 
The laboratory is developing theoretical models of morphogenesis, combining physics, mechanics and advanced numerical simulations. To understand how morphology controls biological functions, and, ultimately, how multicellular systems self-organize, we aim at integrating molecular, cellular and multicellular levels of description into a new and versatile simulation framework for embryo morphogenesis: Virtual Embryo.

\section{From molecular to mesoscopic models of the actomyosin cortex}

As elegantly illustrated by D'Arcy Thompson back in 1917, cells in suspension or in tissues adopt spatial configurations remarkably similar to soap bubbles, an analogy which can be drawn from the physical concept of surface tension. In animal cells, the surface tension is mainly provided by the contractile forces generated by molecular motors within the actin-myosin (or actomyosin) cortex, a thin layer of polymeric filaments, which lies under the plasma membrane. In contrast to passive objects like bubbles, cortical tension is actively regulated in space and time by several biochemical pathways - such as the RhoA signaling cascade - and strongly depends on the deformations of the layer. From a biological perspective, the tools available to perturb the cortex operate at the molecular level (chemical drugs, genetic engineering and environmental cues). Characterizing quantitatively how the selforganization and regulation of molecular players in the cortex (actin filaments, myosin motors, crosslinkers...) control its coarse-grained physical properties (elasticity, fluidity, contractility...) represents therefore a critical step to directly relate experiments to quantitative models.

At the cellular scale, the recent active-gel hydrodynamic theories have proven their efficiency in capturing the essential physics of various actomyosin based dynamical cell processes (Turlier et al., 2014). However their relation to microscopic properties of actomyosin networks remains unclear, and no generic tool is available to simulate the mechanics of active surfaces in 3 dimensions. Combining physics and numerical simulations, we aim at filling these gaps in the next years in close collaboration with experimental groups.

\section{From cellular to multicellular models of morphogenesis}

At the multicellular level, morphogenesis is furthermore regulated by mechanical interaction and biochemical communication between cells, and by external mechanical constraints. In particular, the interplay between cell contractility, cellcell adhesion, molecular expression and fate specification remains poorly understood in early embryos and small tissues. To identify and understand the minimal selforganization principles driving multicellular morphogenetic processes, it is essential to develop realistic 4-dimensional models of interacting cells, offering general and accurate description of cell surface mechanics but also complemented by versatile options to model surface signaling dynamics and simple gene networks regulation.

The morphogenesis of early embryos is the main biological focus and guideline for developing new theoretical tools in the laboratory. In mammalian species, early embryos develop over several days, which leads to a decoupling between morphogenetic timescales (several hours) and typical viscous relaxation timescales (a few minutes). Dynamics is limited in this case first by the slow regulation of surface 
tensions, and morphogenesis is well captured by a quasi-static mechanical description, as we recently proposed for compaction and for the formation of the inner-cell mass in the mouse embryo (Maître, Turlier et al., 2016). At the opposite, most non-mammalian embryo types, such as marine animals or insects, develop on much shorter timescales, of the order of a few hours. In this case, viscous dissipation becomes essential to consider again as it constitutes a main factor limiting cell shape dynamics (Turlier $e t$ $a l ., 2014)$. On such timescales, the biophysical characterization and precise modeling of cell divisions and its mechanical coupling to the rest of the embryo is an essential point that we aim to integrate into realistic simulations of embryo morphogenesis.

\title{
Références citées
}

Turlier H., Audoly B., Prost J. et Johnny J.-F., « Furrow constriction in animal cell cytokinesis », Biophysical Journal, vol. 106, $\mathrm{n}^{\mathrm{o}}$ 1, 2014, p. 114-123, DOI : 10.1016/j. bpj.2013.11.014.

Maître J.-L., Turlier H., IllukKumbura R., Eismann B., Niwayama R., NÉdélec F. et HIIRAGI T., «Asymmetric division of contractile domains couples cell positioning and fate specification », Nature, vol. 536, n 7616, 2016, p. 344-348, DOI : 10.1038/nature18958.

\section{DYNAMIQUE ET PHYSIOPATHOLOGIE DES RÉSEAUX NEURONAUX / DYNAMICS AND PHYSIOPATHOLOGY OF NEURONAL NETWORKS}

\author{
Responsable : Laurent VENANCE
}

\section{RECHERCHE}

Page web : https://www.college-de-france.fr/site/en-cirb/venance.htm.

Our main interest is how neural networks of the brain support its cognitive capacities. We aim at providing rational mechanistic explanations of adaptative control of behavior. Procedural learning corresponds to the acquisition of skills through repeated performance and practice of a behavior in response to external cues, such as biking or playing an instrument. Basal ganglia, a set of subcortical nuclei, participate in the detection of environmental cues and in the selection of appropriate actions based on motivation and reward, thanks to their reciprocal connections to the cerebral cortex and limbic system. Cortex-basal ganglia loops are involved in the adaptive control of behavior and are the main substrate for procedural learning. We therefore focus our work on dissecting the processing of information in cortico-basal ganglia circuits, from sub-cellular to neural network levels. The key roles of basal ganglia are highlighted by motor and cognitive disorders observed in pathologies such as Parkinson diseases, for which no fully satisfying treatments are available yet.

Our main focus is about the role of the striatum, the primary input nucleus of basal ganglia, which is a strategic gate extracting pertinent information and a major site of memory formation. Indeed, striatum acts as a coincidence detector of distributed patterns of cortical and thalamic activity and is in charge to extract pertinent information from background noise at a t time in a given situation, which will give 
rise to an action in adequation with the environment. Our first aim was to investigate the biological processes at play to set the striatal filter which allows this proper signal/noise detection. The strenght of the striatal filter depends mainly on the corticostriatal synaptic efficacy changes. Corticostriatal long-term plasticity provides a fundamental mechanism for the function of the basal ganglia in action selection and in procedural learning. Our last publications focused on the characterization of striatal synaptic plasticity repertoire at play in physiological and pathophysiological conditions.

\section{PUBLICATIONS}

Xu H., Perez S., Cornil A., Detraux B., Prokin I., Cui Y., Degos B., Berry H., De KeRCHOVE D'EXAERDE A. et VENANCE L., « Dopamine-endocannabinoid interactions mediate spike-timing-dependent potentiation in the striatum ", Nature Communications, vol. $9, \mathrm{n}^{\circ} 1$, 2018, 4118, DOI : 10.1038/s41467-018-06409-5.

Fino E., Vandecasteele M., Perez S., Saudou F. et Venance L., « Region-specific and state-dependent action of striatal GABAergic interneurons », Nature Communications, vol. 9, $\mathrm{n}^{\mathrm{o}} 1,2018,3339$, DOI : $10.1038 / \mathrm{s} 41467-018-05847-5$.

Vignoud G., VenANCE L.* et TOUBOUL J.D.*, «Interplay of multiple pathways and activitydependent rules in STDP », PLoS Computational Biology, vol. 14, $\mathrm{n}^{\circ}$ 8, 2018, e1006184, DOI : $10.1371 /$ journal.pcbi.1006184. *Co-senior authors

CUi Y., Perez S. et VenANCE L., «Endocannabinoid-LTP mediated by CB1 and TRPV1 receptors encodes for limited occurrences of coincident activity in neocortex », Frontiers in Cellular Neuroscience, vol. 12, 2018, 182, DOI : 10.3389/fncel.2018.00182.

De Backer J.-F., Monlezun S., Detraux B., Gazan A., Vanopdenbosch L., Cheron J., Cannazza G., Valverde S., Cantacorps L., Nassar M., Venance L., Valverde O., Faure P., Zoli M., De Backer O., Gall D., Schiffmann S.N. et De Kerchove D'EXAERDE A., « Deletion of Maged1 in mice abolishes locomotor and reinforcing effects of cocaine », EMBO Reports, vol. 19, n 9, 2018, DOI : 10.15252/embr.201745089.

Cui Y., Prokin I., Mendes A., Berry H. et Venance L., « Robustness of STDP to spike timing jitter », Scientific Reports, vol. 8, no 1, 2018, 8139, DOI : 10.1038/s41598-01826436-y.

Nelson M.J., ValtcheVA S. et Venance L., « Magnitude and behavior of cross-talk effects in multichannel electrophysiology experiments », Journal of Neurophysiology, vol. 118, $\mathrm{n}^{\mathrm{0}} 1$, 2017, p. 574-594, DOI : 10.1152/jn.00877.2016.

Valtcheva S., Paillé V., Dembitskaya Y., Perez S., Gangarossa G., Fino E. et VENANCE L., "Developmental control of spike-timing-dependent plasticity by tonic GABAergic signaling in striatum », Neuropharmacology, vol. 121, 2017, p. 261-277, DOI : 10.1016/j.neuropharm.2017.04.012.

Foncelle A., Mendes A., JędrzeJewska-SzMeK J., Valtcheva S., Berry H., BLACKWELL K.T. et VENANCE L., « Modulation of spike-timing dependent plasticity: Towards the inclusion of a third factor in computational models », Frontiers in Computational Neuroscience, vol. 12, 2018, p. 49, DOI : 10.3389/fncom.2018.00049. 


\title{
DIVISIONS ASYMÉTRIQUES OVOCYTAIRES / ASYMMETRIC DIVISIONS IN OOCYTES
}

\author{
Responsable : Marie-Hélène VERLHAC
}

\section{RECHERCHE}

Page web : https://www.college-de-france.fr/site/en-cirb/Terret-Verlhac.htm.

We study the last stages of murine oogenesis, a process that terminates with the production of functional female gametes required for sexual reproduction. The last step of oogenesis, named meiotic maturation, corresponds to two successive asymmetric divisions without intervening DNA replication. Mammalian meiotic maturation takes place at puberty under periodical hormonal influence. It can be reproduced and followed in vitro on synchronized population of cells. Oocytes are gigantic cells, up to 1000 times larger than most somatic cells, neuron excepted. Oocyte meiotic divisions are extremely asymmetric in size of the daughter cells, which allows the preservation of maternal stores required for embryo development. Oocytes have thus to accomplish two opposite tasks: segregate their chromosomes equally while partitioning their cytoplasm unequally. Furthermore, this tour de force is challenged by the lack of canonical centres of microtubule nucleation, namely centrosomes containing a pair of centrioles. Canonical centrosomes of mitotic cells organize spindle. During 2017/2018, we have identified mechanisms regulating the formation of meiotic spindles in the absence of canonical centrosomes, processes that might have their share in the innate susceptibility of the female gamete to produce errors in chromosome segregation.

\section{1) Shifting meiotic to mitotic spindle assembly in oocytes disrupts chromosome alignment}

In mouse oocytes, devoid of centrioles, spindle microtubules are nucleated from multiple acentriolar MTOCs (MicroTubule Organizing Centers) that are sorted and clustered prior to completion of spindle assembly in an "inside-out" mechanism, ending with establishment of the poles. We used HSET (kinesin-14) as a tool to shift meiotic spindle assembly toward a mitotic "outside-in" mode and analyzed the consequences on the fidelity of the division. We have shown that HSET levels must be tightly gated in meiosis I and that even a slight overexpression of HSET forces spindle morphogenesis to become more mitotic-like; which means rapid spindle bipolarization and pole assembly coupled with focused spindle poles. The unusual length of meiosis I is not sufficient to correct these early spindle morphogenesis defects, resulting in severe chromosome alignment abnormalities. Thus, the unique "inside-out" mechanism of meiotic spindle assembly is essential to prevent chromosomal misalignment and prevent the production of aneuploid gametes (Bennabi, 2018). 


\section{2) Chromosome structural anomalies due to aberrant spindle forces exerted at gene editing sites in meiosis}

We showed in the past that acentriolar MTOCs (aMTOCs) fragment into discrete foci (Łuksza, 2013). These aMTOCs are further sorted and clustered to form spindle poles, thus providing balanced forces for faithful chromosome segregation. To assess the impact of aMTOCs biogenesis on spindle assembly, we genetically induced their precocious fragmentation in mouse oocytes using conditional overexpression of Plk4, a master MTOC regulator. Excessive microtubule nucleation from these fragmented aMTOCs accelerated spindle assembly dynamics. Prematurely formed spindles promoted the breakage of three different fragilized bivalents, generated by the presence of recombined Lox P sites. Reducing the density of microtubules diminished significantly the extent of chromosome breakage. Thus, improper spindle forces can lead to widely described yet unexplained chromosomal structural anomalies with disruptive consequences on the ability of the gamete to transmit an uncorrupted genome (Manil-Segalen, 2018).

\section{PUBLICATIONS}

Manil-SéGalen M., Łuksza M., KanaAn J., Marthiens V., Lane S.I.R., Jones K.T., TERret M.-E., BASTO R. et VERLhAC M.-H., « Chromosome structural anomalies due to aberrant spindle forces exerted at gene editing sites in meiosis », The Journal of Cell Biology, vol. 217, no 10, 2018, p. 3416-3430, DOI : 10.1083/jcb.201806072.

Simerly C., Manil-Ségalen M., Castro C., Hartnett C., Kong D., Verlhac M.-H., LONCAREK J. et SCHATTEN G., « Separation and loss of centrioles from primordidal germ cells to mature oocytes in the mouse », Scientific Reports, vol. 8, $\mathrm{n}^{\circ} 1$, 2018, p. 12791, DOI : 10.1038/s41598-018-31222-x.

Ahmed W.W., Fodor É., Almonacid M., Bussonnier M., Verlhac M.-H., Gov N., VISCO P., VAN WIJLAND F. et BETZ T., «Active mechanics reveal molecular-scale force kinetics in living oocytes », Biophysical Journal, vol. 114, n 7, 2018, p. 1667-1679, DOI : 10.1016/j.bpj.2018.02.009.

Bennabi I., Quéguiner I., Kolano A., Boudier T., Mailly P., Verlhac M.-H.* et TERRET M.-É.*, «Shifting meiotic to mitotic spindle assembly in oocytes disrupts chromosome alignment », EMBO reports, vol. 19, no 2, 2018, p. 368-381, DOI : 10.15252/ embr.201745225. *Co-senior authors.

Al Jord A.* et Verlhac M.-H., « Spindle assembly: Two spindles for two genomes in a mammalian zygote », Current biology, vol. 28, no 17, 2018, R948-R951, DOI : 10.1016/j. cub.2018.07.044. *Corresponding author.

VERLHAC M.-H., «An actin shell delays oocyte chromosome capture by microtubules », The Journal of Cell Biology, vol. 217, no 8, 2018, p. 2601-2603, DOI : 10.1083/jcb.201807016.

Verlhac M.-H. et Terret M.-É. (dir.), Mouse Oocyte Development: Methods and Protocols, New York, Humana Press/Springer Protocols, coll. « Methods in Molecular Biology », 2018, DOI : 10.1007/978-1-4939-8603-3.

Almonacid M.*, Terret M.-É. et Verlhac M.-H., «Control of nucleus positioning in mouse oocytes », Seminars in Cell \& Developmental Biology, vol. 82, 2018, p. 34-40, DOI : 10.1016/j.semcdb.2017.08.010. *Corresponding author. 
Chaigne A., Terret M.-É. et Verlhac M.-H., « Asymmetries and symmetries in the mouse oocyte and zygote », Results and Problems in Cell Differentiation, vol. 61, 2017, p. 285-299, DOI : 10.1007/978-3-319-53150-2_13.

VERLHAC M.-H., "An actin shell delays oocyte chromosome capture by microtubules », Journal of Cell Biology, vol. 217, no 8, 2018, p. 2601-2603, DOI : 10.1083/jcb.201807016.

\title{
HOMÉOPROTÉINES ET PLASTICITÉ CELLULAIRE / HOMEOPROTEINS AND CELL PLASTICITY
}

\author{
Responsables : Sophie VRIZ et Alain JOLIOT
}

\section{RECHERCHE - RÉGULATION DE LA SÉCRÉTION CONVENTIONNELLE ET NON CONVENTIONNELLE DES PROTÉINES}

Page web : https://www.college-de-france.fr/site/en-cirb/joliot-vriz.htm.

Le peroxyde d'hydrogène $\left(\mathrm{H}_{2} \mathrm{O}_{2}\right)$ est aujourd'hui considéré comme un élément clé de la signalisation cellulaire. Sa production et sa dégradation sont finement régulées par chaque cellule. Il contribue à la régulation de processus physiologiques notamment en contrôlant le degré d'oxydation des cystéines au sein des protéines. L'élévation transitoire de $\mathrm{H}_{2} \mathrm{O}_{2}$ est requise pour induire des programmes de régénération chez les vertébrés, améliorer la plasticité cellulaire et favoriser la cicatrisation. Suite à la démonstration du rôle fondamental d' $\mathrm{H}_{2} \mathrm{O}_{2}$ dans les processus de régénération chez le poisson zèbre, nous avons démontré cette année la conservation de tels mécanismes chez les mammifères (Labit et al., 2018). Nous avons développé différentes stratégies pour manipuler les niveaux d' $\mathrm{H}_{2} \mathrm{O}_{2}$ dans le but de mimer la dynamique extrême des niveaux de $\mathrm{H}_{2} \mathrm{O}_{2}$ observée au cours du développement embryonnaire et de la régénération chez l'adulte. De plus, le ciblage de compartiments subcellulaires spécifiques nous permet d'analyser le rôle d' $\mathrm{H}_{2} \mathrm{O}_{2}$ dans le trafic des protéines, notamment des processus de sécrétion des protéines, conventionnelle ou non conventionnelle, tant ex vivo qu'in vivo.

La protéine Sonic Hedgehog (Shh) est un morphogène indispensable à l'initiation de la régénération, notamment par le contrôle des niveaux redox chez l'adulte (Meda et al., 2018 pour revue). En retour, nos résultats préliminaires montraient un effet de la signalisation redox dans la régulation de la sécrétion de Shh (Meda et al., 2018 pour revue). Afin d'étudier plus en détail l'impact de la signalisation redox sur la sécrétion de Shh, nous avons, d'une part, adapté des outils permettant la synchronisation de la sécrétion de Shh et, d'autre part, effectué des mutagenèses ciblées d'acides aminés susceptibles d'être la cible de la signalisation redox.

Certaines voies de sécrétion non conventionnelles impliquent un transfert direct du substrat sécrété au travers de la membrane plasmique. C'est le cas des homéoprotéines, qui, de plus, présentent la particularité de traverser la membrane dans le sens opposé, permettant ainsi leur internalisation et donc, leur transfert entre cellules. Nous avions démontré le rôle du phospholipide PIP2, enrichi dans la face interne de la membrane plasmique, dans la sécrétion des homéoprotéines. Ce même 
lipide est également nécessaire à l'internalisation de ces dernières, suggérant ainsi une forte similitude entre les mécanismes de transfert au travers de la membrane dans des sens opposés. Nous avons récemment observé que l'internalisation des homéoprotéines est aussi modulée par les niveaux redox cellulaires. La membrane plasmique étant un site privilégié de production d' $\mathrm{H}_{2} \mathrm{O}_{2}$, nous testons l'hypothèse d'une régulation des taux de PIP2 par la signalisation redox.

Au cours de cette année, nous avons renforcé notre collaboration avec l'équipe de Ludovic Jullien (ENS, Paris), ce qui a conduit à la validation d'une nouvelle méthode de quantification de la sécrétion des protéines (Li et al., 2018).

\section{Publications}

Meda F., Joliot A. et VRIZ S., « Nerves and hydrogen peroxide: How old enemies become new friends ", Neural Regeneration Research, vol. 12, $\mathrm{n}^{\mathrm{o}}$ 4, 2017, p. 568-569, DOI : 10.4103/1673-5374.205088.

Feng Z., NAm S., Hamouri F., Aujard I., Ducos B., VRiz S., Volovitch M., Jullien L., LiN S., WeISS S. et BENSIMON D., "Optical control of tumor induction in the zebrafish ", Scientific Reports, vol. 7, nº 1, 2017, p. 9195, DOI : 10.1038/s41598-017-09697-x.

Zhang W., Hamouri F., Feng Z., Aujard I., Ducos B., Ye S., Weiss S., Volovitch M., VRIZ S., JULLIEN L. et BENSIMON D., «Control of protein activity and gene expression by cyclofen-OH uncaging », Chembiochem: A European Journal of Chemical Biology, vol. 19, $\mathrm{n}^{\mathrm{o}}$ 12, 2018, p. 1232-1238, DOI : 10.1002/cbic.201700630.

Meda F., Rampon C., Dupont E., Gauron C., Mourton A., Queguiner I., Thauvin M., Volovitch M., Joliot A. et VRIZ S., « Nerves, $\mathrm{H}_{2} \mathrm{O}_{2}$ and Shh: Three players in the game of regeneration », Seminars in Cell and Developmental Biology, vol. 80, 2017, p. 65-73, DOI : 10.1016/j.semcdb.2017.08.015.

VRIZ S., «Redox signalling in development and regeneration», Seminars in Cell \& Developmental Biology, vol. 80, 2018, p. 1-2, DOI : 10.1016/j.semcdb.2017.09.011.

Li C., Mourton A., Plamont M.-A., Rodrigues V., Aujard I., Volovitch M., Le SauX T., Perez F., VRiz S., Jullien L., Joliot A. et Gautier A., « Fluorogenic probing of membrane protein trafficking », Bioconjugate Chemistry, vol. 29, n 6 , 2018, p. 1823-1828, DOI : 10.1021/acs.bioconjchem.8b00180.

Labit E., Rabiller L., Rampon C., Guissard C., André M., Barreau C., Cousin B., Carrière A., Eddine M.A., Pipy B., Pénicaud L., Lorsignol A., Vriz S.*, Dromard C.* et CASTEILLA L.*, "Opioids prevent regeneration in adult mammals through inhibition of ROS production », Scientific Reports, vol. 8, n 1, 2018, 12170, DOI : 10.1038/s41598-018-29594-1.

Roux L.N., Petit I., Domart R., CONCORDET J.-P., Qu J., Zhou H., Joliot A., FerRigno O. et ABERDAM D., « Modeling of aniridia-related keratopathy by CRISPR/Cas9 genome editing of human limbal epithelial cells and rescue by recombinant PAX6 protein », Stem Cells, vol. 36, no 9, 2018, p. 1421-1429, DOI : 10.1002/stem.2858. 


\title{
RYTHMES CÉRÉBRAUX ET CODAGE NEURAL DE LA MÉMOIRE / BRAIN RHYTHMS AND NEURAL CODING OF MEMORY
}

\author{
Responsable : Michaël ZUGARO \\ Équipe : Nadia Benabdallah, Ariane Bochereau, Céline Boucly, Céline Drieu, \\ Ombeline HoA, Eulalie Leroux, Gabriel MAKDAH, Chantal Milleret, Virginie \\ Oberto, Marco Pompili, Susan Sara, Ralitsa Todorova, Diane Vilmer, Sidney \\ WIENER, Michaël Zugaro.
}

\section{RECHERCHE}

Page web : https://www.college-de-france.fr/site/en-cirb/zugaro.htm.

\section{Introduction}

Les «cellules de lieu» de l'hippocampe codent la position de l'animal dans l'environnement. Lorsqu'un rat se déplace, en raison de leur organisation temporelle singulière, les cellules de lieu s'activent très rapidement l'une après l'autre pour représenter la trajectoire en cours à une vitesse accélérée, ce qui favorise le renforcement de leurs connexions et pourrait sous-tendre la formation d'une première trace mnésique dans l'hippocampe. Ensuite, au cours du sommeil à ondes lentes, ces mêmes séquences se reproduisent spontanément pendant les ondulations, des oscillations hippocampiques de haute fréquence $(200 \mathrm{~Hz})$. Ces réactivations permettent un dialogue avec le cortex qui conduit à la consolidation de la mémoire, c'est-à-dire sa stabilisation à long terme - nous avons été les premiers à le démontrer lors de nos travaux précédents (Eschenko et al., 2008 ; Girardeau et al., 2009 ; Ramadan et al., 2009 ; Girardeau et al., 2014 ; Maingret et al., 2016).

Des structures sous-corticales jouent également un rôle fondamental dans ce processus, comme le striatum ou les noyaux neuromodulateurs. Nos travaux ont mis en évidence des couplages pendant le sommeil entre l'activité spontanée des neurones noradrénergiques, les ondulations hippocampiques, et les réactivations d'ensembles neuraux au niveau cortical (Mölle et al., 2006 ; Peyrache et al., 2009 ; Eschenko et al., 2012).

\section{Mise en place et réactivation des séquences hippocampiques}

Les séquences hippocampiques pourraient donc contribuer à la formation des traces mnésiques initiales, qui sont ensuite consolidées pendant le sommeil. Pour le tester, nous avons développé un protocole unique pour perturber sélectivement la formation des séquences hippocampiques au cours de l'exploration, et évaluer l'impact de cette perturbation sur les réactivations pendant le sommeil. Nous avons montré qu'en l'absence de séquences hippocampiques pendant l'exploration, on n'observe aucune réactivation pendant le sommeil. L'organisation temporelle spécifique des séquences hippocampiques est donc nécessaire à la formation des souvenirs. 


\section{Dialogue hippocampo-cortical pour la consolidation des traces mnésiques}

L'hippocampe et le cortex préfrontal médian dialoguent pendant le sommeil, ce qui permet la consolidation de la mémoire. Or, au cœur même de ce dialogue se produit une brusque interruption d'activité nommée « onde delta », et dont le rôle semble paradoxal. Nous avons découvert que, contrairement à un postulat généralement accepté, les ondes delta ne s'accompagnent pas de silence total, mais que de petits groupes de neurones corticaux poursuivent leur activité. Nos données indiquent que ces neurones, qui ont été particulièrement activés pendant l'apprentissage, participent au dialogue avec l'hippocampe, et que l'onde delta pourrait servir à les isoler des autres neurones pour éviter les interférences et faciliter la consolidation de la mémoire.

\section{Le réseau hippocampe-striatum-préfrontal dans l'apprentissage et la flexibilité cognitive}

L'apprentissage de différentes règles et la capacité à changer de stratégie en fonction du contexte mettent en jeu le cortex préfrontal, qui sous-tend certaines fonctions exécutives, ou encore le striatum, qui intervient dans la prise de décision et la motivation. Ces structures sont également impliquées dans les processus mnésiques, via leurs connexions avec l'hippocampe. Nous avons enregistré des neurones simultanément dans ces trois structures lors de l'apprentissage de deux règles différentes et du choix d'une règle en fonction du contexte. Nos résultats indiquent que les apprentissages successifs et le changement de stratégie sont soustendus par de multiples éléments du réseau cortico-striatal, et non par une seule structure. L'activité dans ces régions présente un décours temporel variable, qui dépend du niveau d'apprentissage et de la règle en cours. Enfin, la communication entre structures varie avec l'étape d'apprentissage et lors du changement de stratégie.

\section{PuBLiCATIONS}

Drieu C., Todorova R. et Zugaro M., « Nested sequences of hippocampal assemblies during behavior support subsequent sleep replay », Science, vol. 362, n 6415,2018 , p. 675679, DOI : 10.1126/science.aat2952.

TOdorova R. et Zugaro M., " Hippocampal ripples as a mode of communication with cortical and subcortical areas », Hippocampus [En ligne], 2018 ; Hippocampus, vol. 30, $\mathrm{n}^{\circ} 1$, 2020, p. 39-49, DOI : 10.1002/hipo.22997.

WIENER-VACHER S.R. et WIENER S.I., "Video head impulse tests with a remote camera system: Normative values of semicircular canal vestibulo-ocular reflex gain in infants and children », Frontiers in Neurology, vol. 8, 2017, p. 434, DOI : 10.3389/fneur.2017.00434.

MilleRET C. et BUI QUOC E., «Beyond rehabilitation of acuity, ocular alignment, and binocularity in infantile strabismus », Frontiers in Systems Neuroscience, vol. 12, 2018, DOI : 10.3389/fnsys.2018.00029. 



\title{
INSTITUT DE PHYSIQUE
}

\section{MATIÈRE QUANTIQUE SOUS CHAMP MAGNÉTIQUE / QUANTUM MATTER UNDER MAGNETIC FIELD}

\author{
Responsable : Benoît FAUQUÉ
}

\begin{abstract}
RECHERCHE
Page web : https://www.college-de-france.fr/site/young-team-incubator/ Presentation_4.htm.

Le groupe Matière quantique sous champ magnétique de l'IPCF s'intéresse aux propriétés électroniques des métaux dilués en présence d'un champ magnétique. Sous l'effet du champ magnétique, les électrons se déplacent le long d'une hélice dont le rayon est donné par le rayon cyclotronique (Rc). À mesure que le champ magnétique augmente, Rc diminue, croisant les différentes échelles caractéristiques du matériau. À faible champ magnétique, lorsque $\mathrm{r}_{\mathrm{c}}$ est comparable au libre parcours moyen électronique $\left(l_{e}\right)$, la dynamique de l'électron est bien décrite par une approche semi-classique. Â plus fort champ magnétique, lorsque Rc devient comparable à la longueur d'onde de Fermi $\left(\lambda_{\mathrm{F}}\right)$, on s'attend à une modification de l'état fondamental électronique du système. C'est dans ce régime dit de la «limite quantique » que l'effet Hall quantique est observé à deux dimensions. Paradoxalement, cette limite a été peu étudiée à trois dimensions, essentiellement pour une raison pratique : dans le cas du cuivre (ou d'un métal standard), le champ magnétique nécessaire pour atteindre cette limite est de l'ordre de 5000 T. En revanche, dans le cas des métaux dilués, celui-ci est beaucoup plus faible, de l'ordre de quelques teslas. Nous explorons donc l'organisation des électrons dans le régime de la limite quantique dans les métaux dilués en particulier dans le graphite où nous avons mis en évidence l'existence de phases électroniques originales induites par le champ magnétique.
\end{abstract}

\section{Publications}

Lin X., Rischau C.W., Buchauer L., JaOui A., Fauqué B. et Behnia K., « Metallicity without quasi-particles in room-temperature strontium titanate », NPJ Quantum Materials, vol. 2, no 1, 2017, p. 41, DOI : 10.1038/s41535-017-0044-5.

Collignon C., Fauqué B., Cavanna A., Gennser U., Mailly D. et Behnia K., "Superfluid density and carrier concentration across a superconducting dome: the case of $\mathrm{SrTi}_{1-\mathrm{x}} \mathrm{Nb}_{\mathrm{x}} \mathrm{O}_{3}$ », Physical Review B, vol. 96, no 22, 2017, 224506, DOI : 10.1103/ PhysRevB.96.224506 [arXiv: 1703.00863].

LeBoeuf D., Rischau C.W., Seyfarth G., Küchler R., Berben M., Wiedmann S., TABIS W., Frachet M., BeHNIA K. et FAUQUÉ B., « Thermodynamic signatures of the fieldinduced states of graphite », Nature Communications, vol. 8, $\mathrm{n}^{\circ}$ 1, 2017, 1337, DOI : 10.1038/ s41467-017-01394-7 [arXiv: 1705.07056]. 
ZHu Z., FAuqué B., BehNiA K. et FusEYA Y., « Magnetoresistance and valley degree of freedom in bulk bismuth », Journal of Physics: Condensed Matter, vol. 30, $\mathrm{n}^{\mathrm{O}}$ 31, 2018, 313001, DOI : 10.1088/1361-648X/aaced7 [arXiv: 1801.07098].

Collignon C., Lin X., Rischau C.W., Fauqué B. et Behnia K., « Metallicity and superconductivity in doped strontium titanate », Annual Review of Condensed Matter Physics, vol. $10, \mathrm{n}^{\mathrm{o}}$ 1, 2019, p. 25-44, DOI : 10.1146/annurev-conmatphys-031218-013144 [arXiv: 1804.07067].

\section{RECHERCHES SUR LA PHYSIQUE MÉSOSCOPIQUE À PARTIR DE GRAPHĖNE ET DE JONCTIONS JOSEPHSON / JOSEPHSON JUNCTION SPECTROSCOPY OF MESOSCOPIC SYSTEMS}

Responsable : Çağlar GiRiT

\section{RECHERCHE}

Page web : https://www.college-de-france.fr/site/young-team-incubator/ Presentation_2.htm.

\section{PHOTONIQUE QUANTIQUE / QUANTUM PHOTONICS}

Responsable : Alexei OURJOUMTSEV

\section{RECHERCHE}

Page web : https://www.college-de-france.fr/site/young-team-incubator/ Presentation_3.htm.

\section{PHYSIQUE QUANTIQUE}

Responsable : Jean-Michel RAIMOND

\section{RECHERCHE}

Page web : https://www.college-de-france.fr/site/physique-quantique/Presentation.htm.

Notre activité s'est orientée en 2017-2018 vers trois directions principales : jeux quantiques dans les multiplicités de Rydberg; électrodynamique quantique en cavité ; simulation quantique avec les atomes de Rydberg. 
Nous avons obtenu depuis 2016 des résultats importants dans la première direction, soutenue par un contrat ANR jeune (PI : S. Gleyzes) et un ITN européen (QUSCO). Nous avons en particulier observé l'oscillation de Rabi cohérente entre un niveau de faible moment angulaire et le niveau circulaire de moment angulaire maximum. Nous avons réalisé un électromètre fondé sur des états «chat de Schrödinger », avec une sensibilité au-delà de la limite quantique standard.

Nous avons récemment étendu le champ d'application de cet électromètre. En manipulant temporellement le dipôle électrique de l'atome, nous mesurons directement la fonction de corrélation temporelle du champ, avec une bande passante de $5 \mathrm{MHz}$. Nous pouvons ainsi reconstruire complètement les propriétés statistiques d'un champ stochastique. Ce résultat ouvre des voies prometteuses pour la mesure de signaux aléatoires en physique mésoscopique. Un article a été soumis.

Nous avons réalisé un magnétomètre, fondé sur une superposition des deux niveaux circulaires de moments angulaires opposés. Dans une image classique, l'électron tourne sur l'orbite circulaire du modèle de Bohr dans les deux sens en même temps. Un seul des atomes dans cet état «chat de Schrödinger » fournit une mesure du champ magnétique aussi sensible que celle de 1000 atomes dans un magnétomètre conventionnel. Ces résultats ont été publiés depuis dans la revue Nature Physics.

Enfin, en étroite collaboration avec le groupe de Christiane Koch (Univ. Kassel), nous appliquons des techniques de contrôle quantique pour améliorer considérablement la préparation des atomes circulaires à partir de niveaux accessibles par laser, en évitant les imperfections liées aux défauts quantiques de niveaux de faible moment angulaire. Nous avons pu ainsi préparer, avec les impulsions radiofréquence calculées par le groupe de Kassel, des niveaux circulaires avec une fidélité de $95 \%$ en 120 ns, un résultat sans précédent. Nous pouvons concevoir des impulsions préparant des états plus complexes, comme les superpositions circulaires/état de grand dipôle au cœur de notre électromètre. Ces résultats sont en cours de rédaction.

Dans la première de nos expériences d'électrodynamique quantique en cavité, un atome traversant deux cavités intrique leur état. Nous avons réalisé une superposition où un photon est dans une cavité ou dans l'autre, et nous développons en collaboration avec P. Rouchon (Mines-Paristech) une méthode efficace de reconstruction de l'état quantique joint des deux cavités. Les résultats de cette reconstruction sont soumis. Nous allons étendre notre activité à des expériences de thermodynamique quantique (soutenues par un contrat ANR QUDICE - PI : Igor Dotsenko), où nous utiliserons les atomes pour échanger travail et chaleur entre les deux cavités.

En tirant parti du grand temps d'interaction entre des atomes de Rydberg lents et une cavité, nous avons résolu par spectroscopie micro-onde la transition d'un atome en présence d'un nombre donné de photons. Nous sélectionnons ainsi un nombre de photons donné en détectant un seul atome. En modulant dans le temps la fréquence de l'atome, nous travaillons à préparer des états plus complexes, superpositions de deux états de Fock différents, par exemple. Un premier papier sur ces résultats est soumis.

Notre dernière activité doit devenir notre principale ligne d'investigation dans un futur proche. Il s'agit de la réalisation d'un simulateur quantique de chaîne (ou de réseaux) de spins. Elle est soutenue par un contrat QUANTERA (ERYQSENS), par une ANR (TRYAQS), une action du réseau SIRTEQ (CARAQUES), une action du 
Flagship sur les technologies quantiques (PASQUANS) et, enfin, par un contrat ERC Advanced (TRENSCRYBE) porté par M. Brune qui prendra la direction de l'équipe au $1^{\text {er }}$ janvier 2019. Nous envisageons de piéger par laser des atomes de Rydberg circulaires dans un condensateur plan qui inhibe leur émission spontanée. La durée de vie des atomes peut atteindre une minute, un résultat remarquable. Nous proposons une méthode déterministe de préparation et de détection d'une chaîne contenant jusqu'à une quarantaine d'atomes. Les interactions dipolaires entre ces atomes, un habillage micro-onde et un choix optimal de niveaux rendent la chaîne équivalente à un ensemble de spins interagissant entre plus proches voisins de la façon la plus générale, avec des temps caractéristiques très courts à l'échelle du temps de vie de la chaîne. Sa dynamique simule donc un des systèmes paradigmatiques de la physique de la matière condensée, suffisamment complexe pour qu'une approche numérique classique soit difficile dans le cas général en raison de la taille gigantesque de l'espace de Hilbert. Tous les paramètres du Hamiltonien peuvent être contrôlés en temps réel, ouvrant des perspectives nouvelles pour la simulation quantique. Un article important résumant la proposition a été publié. Du point de vue expérimental, nous travaillons sur la première expérience de piégeage d'un atome circulaire. Nous avons conçu une expérience de pinces optiques, qui nous permettra très rapidement d'étudier l'interaction entre atomes circulaires piégés.

\section{PUBLICATIONS}

Patsch S., Reich D.M., Raimond J.-M., Brune M., Gleyzes S. et Koch C.P., «Fast and accurate circularization of a Rydberg atom », Physical Review A, vol. 97, no 5, 2018, 053418, DOI : 10.1103/PhysRevA.97.053418 [arXiv: 1802.09504].

Nguyen T.L., Raimond J.M., SAYrin C., Cortiñas R., Cantat-Moltrecht T., Assemat F., Dotsenko I., Gleyzes S., Haroche S., Roux G., Jolicoeur T. et Brune M., «Towards quantum simulation with circular Rydberg atoms », Physical Review X, vol. 8, n 1, 2018, 011032, DOI : 10.1103/PhysRevX.8.011032 [arXiv: 1707.04397].

Dietsche E.K., LARrouy A., RAimond J.M., Brune M. et GleyZeS S., « Quantum-enabled electrometer measures field transients and correlation function », 2018, http://arxiv.org/ abs/1805.06870. 